\title{
ERRATUM TO: A TWO-STEP BAYESIAN APPROACH FOR PROPENSITY SCORE ANALYSIS: SIMULATIONS AND CASE STUDY
}

\author{
DAVid Kaplan AND Jianshen CHEN
}

DEPARTMENT OF EDUCATIONAL PSYCHOLOGY, UNIVERSITY OF WISCONSIN-MADISON

\section{Erratum to: PSYCHOMETRIKA 2012 DOI 10.1007/s11336-012-9262-8}

In Equation (19) of the paper, the denominator $m$ should be deleted. In the BPSA-1 hybrid approach, we view the treatment effect estimate $\hat{\gamma}$ as the posterior mean of $\gamma$ based on the posterior distribution of propensity score model parameters rather than the frequentist-based mean of $\hat{\gamma}_{j}$ as shown in Equations (14) and (15). We utilize the total variance formula to estimate the variance of $\hat{\gamma}$ in BPSA-1. Then

$$
\operatorname{Var}(\hat{\gamma})=E\{\operatorname{Var}(\hat{\gamma} \mid \eta)\}+\operatorname{Var}\{E(\hat{\gamma} \mid \eta)\}
$$

From Equation (16) to (18) with $\hat{\gamma}_{1}$ replaced by $\hat{\gamma}$ we obtain the corrected Equation (19)

$$
\operatorname{Var}(\hat{\gamma})=m^{-1} \sum_{j=1}^{m} \hat{\sigma}_{j}^{2}+(m-1)^{-1} \sum_{j=1}^{m}\left(\hat{\gamma}_{j}-m^{-1} \sum_{j=1}^{m} \hat{\gamma}_{j}\right)^{2} .
$$

All the results presented in the tables are correct and based on this variance expression.

The online version of the original article can be found under doi:10.1007/s11336-012-9262-8.

Requests for reprints should be sent to David Kaplan, Department of Educational Psychology, University of Wisconsin-Madison, 1025 W. Johnson St., Madison, WI 53706, USA. E-mail: dkaplan@education.wisc.edu 